\title{
Assessing the Links among Maternal Nonstandard Work Schedules, Early Learning Environments and Young Children's Academic Achievement
}

\begin{abstract}
An emerging body of research on the effects of maternal nonstandard work suggests that young children's cognitive development may be negatively impacted. Additionally, evidence suggests that there may be varying patterns of child care utilization among mothers who work nonstandard schedules compared to those working standard schedules. Yet, to date, very little research has specifically examined the extent to which early learning environments help explain any associations between nonstandard work and child outcomes. To address this gap, the current study seeks to examine the relationship between maternal nonstandard work schedules and a salient aspect of the broader domain of academic readiness - preschool-aged children's early academic skills, as well as the potential mediating role of early learning environments (as experienced by children in child care and at home). Using nationally representative data from the Early Childhood Longitudinal Study - Birth Cohort (ECLS-B), a series of structural equation models were utilized to investigate the study aims. Results showed that early care and education learning environments and home learning environments partially mediated the relationship between maternal nonstandard work schedules and children's early academic skills. That is, children of mothers working nonstandard hours scored lower on assessments of academic skills than children of mothers working standard hours, and this appears to be partially explained by their reduced access to child care and home environments that emphasize early learning. The results from this study indicate the importance of measuring contextual influences in order to fully understand how maternal nonstandard work schedules are linked to children's early academic skills.
\end{abstract}

Keywords: Maternal nonstandard schedules; Early learning environments; Academic achievement; Family stress

Research Article
Volume 8 Issue 2 - 2017
Nina Smith ${ }^{1 *}$, Danielle Crosby'2 , Catherine-
Scott-Little ${ }^{2}$, Chris Payne ${ }^{3}$ and Jonathan
Livingston $^{4}$
${ }^{1}$ Department of Human Sciences, North Carolina Central
University, USA
${ }^{2}$ Department of Human Development and Family Studies,
University of North Carolina at Greensboro, USA
${ }^{3}$ Center for Youth, Family and Community Partnerships,
University of North Carolina at Greensboro, USA
${ }^{4}$ Department of Psychology, North Carolina Central University,
USA
*Corresponding author: Nina Smith, Department of Human
Sciences, North Carolina Central University, 1801 Fayetteville
Street, Dent Building, Room 205, Durham, NC 27707,
USA, Tel: 1-919-530-7147; Fax: 1-919-530-7983; Email:
nsmith42@nccu.edu
Received: September 14, 2017 | Published: October 16,
2017

\section{Introduction}

Social scientists have well established that the proximal and distal environments children experience at a young age have lasting effects on their later development. In contemporary U.S. society, child care serves as a focal environment for children aged birth to five [1]. In contrast to prior decades, a majority of children today spend substantial amounts of time in early care and education settings before school entry, often beginning in infancy. In 2002, approximately 10 million children under the age of five were in child care for an average of 32 hours per week. These trends have been largely shaped by the changing economic landscape, particularly for women. For example, in 1975, approximately 20 percent of mothers with children under the age of 6 held a paid job [2]. Three decades later, this number had more than tripled, to a rate of $64 \%$ [3]. While young children with employed mothers spend roughly twice as much time in child care as those whose mothers are not employed, it is notable that children in the latter group still spend an average of 18 hours per week in a care setting [4]. These findings emphasize the important role that child care plays in the daily lives of many
American families. Questions about the long-term effects of child care on children's later academic and social outcomes are of great interest to researchers, practitioners, and policymakers and have been the focus of considerable research in recent decades. Initial research on child care was driven by the increase in women's paid labor force participation. The original line of inquiry was whether time away from mothers would be harmful to children. Given no evidence that child care per se is positive or negative for children's development, more recent lines of inquiry have focused on the type and quality of care that children experience and the extent to which different arrangements meet the needs of children and their families. One central focus of this literature has been parental employment (particularly maternal employment) and its role in shaping the child care decision of families with young children. In recent years, societal-level changes in the timing and scheduling of work have created new demands for families, raising questions about the implications of nonstandard work schedules for children and family life. A small, emerging body of research on maternal nonstandard work suggests that there may be varying patterns of child care utilization among mothers who work nonstandard schedules compared to those working standard schedules, with 
higher incidences of parental care (e.g., maternal or paternal care) among two-parent families and relative care among singleparent families among those working nonstandard schedules. These decisions are often a complex negotiation of preferences, resources, and constraints. Indeed, studies have revealed that some parents choose to work nonstandard hours to acquire the best care arrangements for their children, but the majority find themselves working nonstandard schedules because their jobs require it [5]. In addition, several studies indicate that the timing and extent of maternal nonstandard work schedules is linked to lower levels of young children's cognitive well-being [6]. Yet, to date, very little research has specifically examined the extent to which early care and education experiences help explain any associations between nonstandard work and child outcomes. The present study seeks to address existing gaps in the literature by providing a holistic examination of the relationships among these variables. Its specific purpose is to examine the linkages between maternal nonstandard work schedules, the learning environments preschool-children experience in child care settings and at home, and children's early academic skills at age four. Using nationally representative data from the Early Childhood Longitudinal StudyBirth Cohort (ECLS-B), a series of structural equation models were utilized to investigate the study aims (Figure 1).

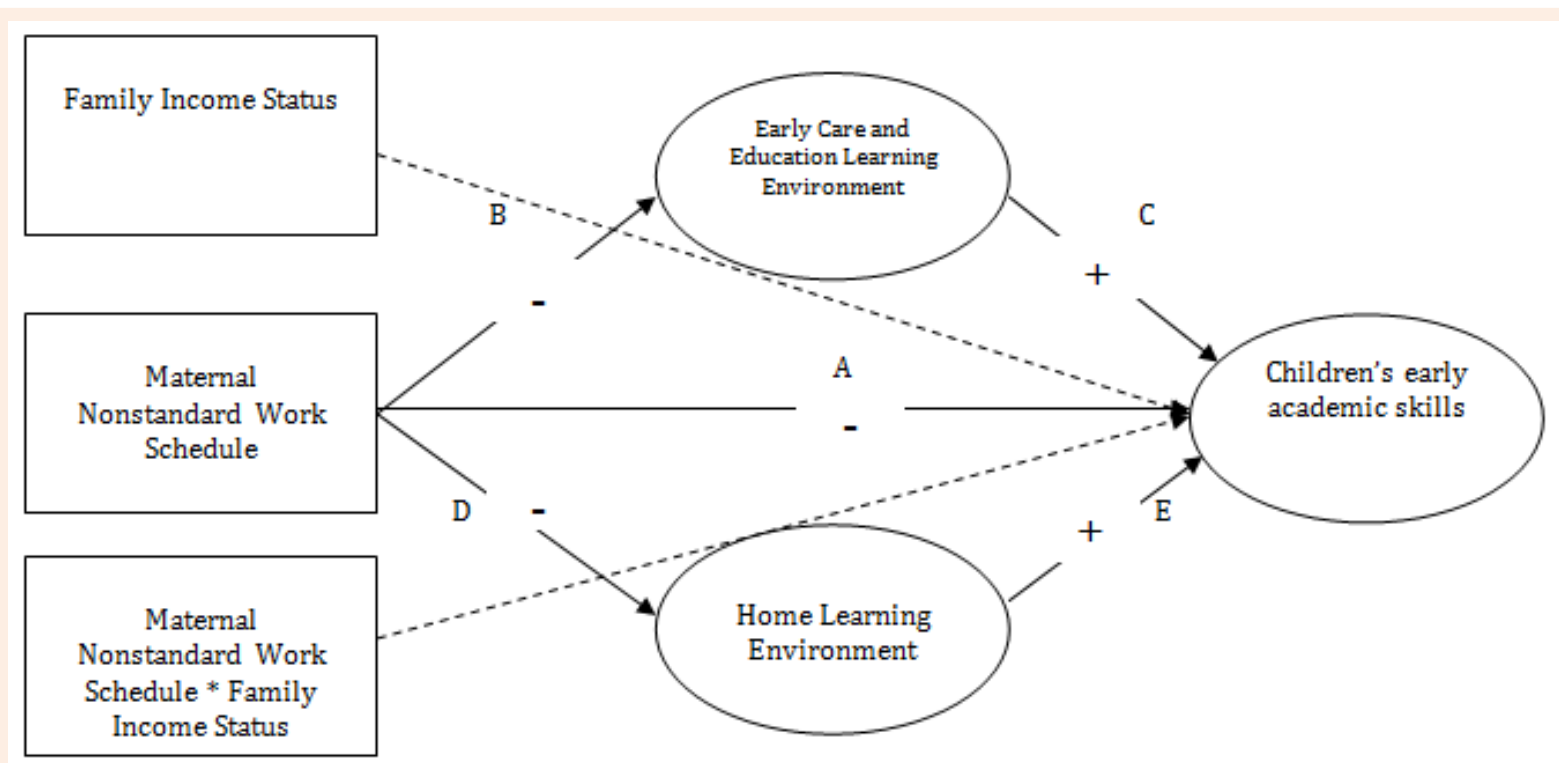

Figure 1: Conceptual model depicting the hypothesized associations among maternal nonstandard work schedules, early care and education learning environments, home learning environments, and children's early academic skills: Family income status as a potential moderator.

\section{Theory}

The current study on maternal nonstandard work schedules, early learning environments, and children's early academic skills is grounded in the family stress model. This perspective seeks to understand how the amount and type of stress experienced by the family system, as mediated by family resources and processes, shape their coping patterns and perceptions, as well as the ease of adaptation to both normative changes and nonnormative events [7]. There are several extensions of the family stress model that propose various mediating pathways through which family processes affect family adaptability. The current study builds on the original model and its recent extensions to focus on the challenges mothers face in balancing nonstandard work hours and the learning environments of young children. The guiding framework for family stress theory is the Double ABCX model of family stress and adaptation. This model builds on Hill's [8] model of family stress and crisis. Hill [8] initially proposed the ABCX model consisting of precrisis variables, such that stressors:

\section{Existing resources}

2. Perception of stressors

\section{Each precede the onset of a 'crisis' (x).}

The Double ABCX model reconceptualizes the precrisis variables and adds postcrisis variables, such that a crisis producing event results in a pile-up of demands and intervening factors that shape the course of adaptation (e.g. resources, coherence, and meaning). According to the family stress perspective, the amount of stress that families face and its impact on family functioning is determined by the resources available. The stress associated with working a nonstandard schedule may be positive or negative for mothers of young children. Many parents prefer to share the care of their children between them, and working a nonstandard schedule may facilitate such a preference [9]. Not all parents, however, may want or are able to share child care between them; especially single mothers. In fact, roughly two thirds of parents work nonstandard schedules out of necessity, rather than choice and would rather not work these times [5-10]. Therefore, most mothers who work nonstandard schedules are charged with the complex task of arranging child care during times when care is often unavailable and/or unfavorable [11,12]. Many jobs that require nonstandard schedules generally pay low-wages and are low in complexity, which may add to the financial stress of 
mothers occupying such schedules. Whereas dual-earner couples and families with higher income levels are better equipped with resources and strategies to adequately adapt to pile-up, the stress associated with working a nonstandard schedule may be more severe among single parent and low-income families [10].

\section{Maternal nonstandard schedules and child outcomes}

Interests in the implications of maternal employment for young children originated with a concern about the negative developmental effects of time spent away from the mother as the primary caregiver and attachment figure. It is nearly impossible for mothers to engage in the labor force while simultaneously providing continuous care for young children, meaning that alternate arrangements with nonmaternal (often nonparental) caregivers must be made. When early studies of the overall effects of maternal employment and nonmaternal caregiving found few clear impacts (either positive or negative) on child development, researcher's attention turned to a more detailed exploration of the characteristics of mothers' employment and children's care environments. For example, previous studies examined the timing at which mothers return to the work force $[13,14]$ and the intensity of their work efforts (e.g., parttime versus full-time employment). Several studies have found positive associations between maternal employment and children's cognitive development, with the caveat that intensive maternal employment in the first year of life may be associated with more negative child outcomes [13,14]. Only recently have researchers begun to focus on timing and regularity of parents work schedules and their possible effects on child well-being. Part of this interest has stemmed from significant changes in the U.S. labor market in recent decades. The U.S. continues to transition to a service economy, which Presser terms the "24/7 economy." Accompanying the 24/7 economy is a great demand for service sector jobs, which are likely to demand nonstandard work hours. Approximately one fifth of workers in the U.S. occupy a nonstandard schedule, which is defined as instances in which at least half of a worker's hours fall outside of the $8 \mathrm{am}$ to $4 \mathrm{pm}$ range [14-17]. Socially and economically disadvantaged segments of the population are most likely to work nonstandard schedules. For example, single parents, mothers with low levels of education, and minorities are disproportionately overrepresented in low-wage occupational sectors [5-17]. More importantly, decisions around child care for this group are complex because care is difficult to secure during nonstandard hours. Therefore, understanding the child care decisions of mothers who work nonstandard hours and how those decisions effect children's later development is vital.

\section{Early learning environments as predictors of early school success}

Researchers have long sought to understand the factors that best predict the cognitive, social, emotional, and physical development of young children. In recent years, these aspects of development have been increasingly linked to the concept of school readiness. Broadly defined, school readiness refers to the salient dimensions of development that prepare young children for entry into school and later school success. Research has recently extended the concept of school readiness to encompass the contexts in which children live and the people with whom they interact (parents, siblings, caregivers, etc.). Early learning environments play a vital role in children's development, as a large number of children spend time in nonmaternal care [18]. Therefore, efforts to examine the contribution of early learning environments to child outcomes derive from a general interest in environmental influences on development [19]. Driven by an increase of women entering the workforce, nonparental care of young children has become the norm in recent decades. Initially, this shift provoked controversy among researchers about the benefits and risks associated with nonparental child care. Early research focused on the timing and quantity of early care, suggesting that early onset and extensive care might yield adverse consequences for children's development. For example, Belsky [20] warned that entry into child care during the first year of life could lead to attachment and withdrawal issues during preschool years. Other studies supported these early findings, suggesting that longer hours in care yield unfavorable outcomes [21]. By contrast, other studies suggested that nonparental care per se did not negatively influence children's development [22]. Instead, researchers argued that children in nonparental care exhibit the same social behaviors as children reared at home [22]. To tease apart these mixed findings, more refined studies followed, which explored the type and characteristics of children's early learning environments. Accumulating evidence suggests that cognitively stimulating early learning environments are vital for children's early academic skills and children in center-based early learning environments during the preschool years exhibit higher levels of cognitive functioning compared to children cared for at home [17- 24]. When other types of early learning environments are explored (e.g. home-based care), children do not show the same increases in cognitive development [24]. These differences in center- and home-based care are largely due to features of the environment. For example, researchers have identified several important elements of early learning environments as fundamental predictors of children's academic skills. Examples include language experiences, where children are provided with beneficial models of communication and provided ample reading and math activities [24]. Other features of early learning environments, such as caregiver education and preparation, are also linked to children's early academic skills. Findings from several studies have shown that children attending early learning programs in which caregivers had more education and training performed better on a range of cognitive measures [23]. Learning environments rich in cognitively stimulating materials and activities and experienced caregivers are the primary mechanisms through which young children acquire emergent reading and math skills and become ready for school [25].

\section{Maternal nonstandard work schedules and early learning environments}

Researchers are increasingly investigating the determinants of early learning environments of children whose parents are employed, namely children of working mothers [26]. Mothers are charged with the task of selecting favorable early care and education learning environments while also managing home environments and other family demands. Understanding the role 
that these considerations play is vital, given the importance of the early learning environments on children's later development. Much of the practical decision making around child care arrangements is guided by competing demands. Employment is a leading demand of mothers with young children, as two thirds of working mothers have children in some form of nonparental care [27]. Consequently, young children's early learning environments are largely influenced by parents' work schedules. A large majority of young children spend at least a portion of their time in nonparental care and are cared for in a variety of nonparental early care environments [18]. These early learning environments range from informal care by kith and kin to formal care in centerand family-based settings, with center-based care becoming the predominant early learning environment by the time children are 3 years old or older. Understanding the determinants of the early learning environments of children whose mothers occupy nonstandard schedules is important because prior research has linked certain features of care to children's later cognitive development [24]. Additionally, research suggests that the care arrangements of children whose mothers work nonstandard schedules may differ from those of children whose mothers work standard schedules. For example, results suggest higher use of informal care arrangements among parents who work nonstandard schedules, with a much higher occurrence of father care among married mothers and grandmother care among unmarried mothers [5-29]. Early work by Presser [5-12] revealed that less than $15 \%$ of children with employed mothers were cared for by fathers; however this figure was $40 \%$ for children whose mothers worked nonstandard schedules. Presser's [12] early work also revealed that nearly all fathers who were available to do so provided care for their young children when their wives worked a nonstandard schedule. Parents working nonstandard schedules may need to rely on a variety of care arrangements beyond conventional center- or home-based settings, as the hours of center care may not align with nonstandard schedules. Several studies support these notions suggesting that mothers who work nonstandard schedules have difficulty arranging child care because formal child care is less available during these hours. Therefore, mothers often rely on informal care arrangements or patchworks of care (i.e. multiple care arrangements from friends, relatives or neighbors) which often equates to less reliable care [30,31]. By contrast, Morrissey [32] found multiple care arrangements to be unrelated to nonstandard schedules of mothers. To address these conflicting findings, researchers must further question the causal direction of these associations. Parents may choose nonstandard schedules to accommodate their preference for using parental or relative care. Alternatively, nonstandard schedules may be employed because parents are unable to secure adequate or affordable care during standard hours (i.e. 8a.m. - 5p.m.). Given that nonstandard schedules are associated with lower wages, the latter arrangement is plausible.

\section{Materials and Methods}

The purpose of the current study is to examine:

1. The relationship between maternal nonstandard work schedules and preschool-aged children's early academic skills,

2. The potential mediating role of early learning environments (as experienced by children in child care and home), and

3. The extent to which family income status influences this set of relationships.

Data from the Early Childhood Longitudinal Study, Birth Cohort (ECLS-B) are used to investigate the current research questions. The ECLS-B is a prospective study of a large and diverse sample of approximately 14,000 children, followed from birth to school entry; this sample was drawn using birth certificate data to be representative of the full population of infants born in the United States in 2001. Some subpopulations were oversampled including Asian and Pacific Islander children, American Indian and Alaska Native children, Chinese children, twins, and low and very low birth weight children. Children whose mothers were younger than age 15 at the time of the focal child's birth were excluded from the initial sampling frame [33]. Data were collected at four time points after the birth of the focal child: 9 months (Wave 1), 2 years (Wave 2), approximately 4 years (Wave3), and at kindergarten entry (Wave 4). The current study relies primarily on data from the third wave of the study, though some covariates used in the analysis were assessed during the baseline interview at 9 months. As part of each data collection, home visits were conducted that involved administering direct assessments with children and interviews with parents. Parent data were collected using a computer-assisted personal interview (CAPI) and a parent self-administered questionnaire (SAQ). Primary caregivers/respondents were asked questions regarding household structure, parental education and employment, child care decisions, community characteristics, income, and other sources of support available. The interview also gathered detailed information about the focal child, the primary caregiver, the home environment, parenting beliefs and practices, and characteristics of the family. The respondent had to be familiar about the child's care and education, be 15 years of age or older at the time of the child's birth, and be living in the household with the child. Approximately 95 percent of parent interviews were completed by the child's biological mother. Most of the parent interviews were conducted in English; however, a Spanish version of the CAPI instrument was implemented when required. Special provisions were made for families who spoke languages other than English or Spanish (i.e. a household member or professional translator were used). The response rate for the preschool parent interview (i.e. Wave 3 ) based on the sample successfully recruited to participate at 9 months was 88 percent $(\mathrm{N}=8900)$. Early care and education providers were interviewed by telephone and a subsample of the children had their nonparental care and education arrangements directly observed.

\section{Analysis sample}

The analysis for the current study includes a subsample of Wave 3 participants from the ECLS-B-namely children whose mothers were employed at Wave 3 , who were in some form on nonparental care, and who had complete data on the outcome variables (i.e. direct assessments of preschool academic skills) $(n=4900)$. The analysis therefore excludes the roughly 4, 000 children whose mothers were not employed at Wave 3. Descriptive statistics for the analysis sample are summarized in Table 1. 
Table 1: Descriptive statistics for demographic variables.

\begin{tabular}{|c|c|c|c|c|}
\hline \multirow{2}{*}{ Variables } & \multicolumn{2}{|r|}{ Standard $(n=3,731)$} & \multicolumn{2}{|c|}{ Nonstandard $(n=1,130)$} \\
\hline & $\mathbf{N}^{1}$ & Frequency $(\%)$ or $M(S D)$ & $\mathbf{N}^{1}$ & Frequency (\%) or M(SD) \\
\hline \multicolumn{5}{|l|}{ Child Sex } \\
\hline Female & 1850 & 49.5 & 550 & 50.3 \\
\hline Male & 1900 & 50.5 & 550 & 49.7 \\
\hline \multicolumn{5}{|l|}{ Family Income Status } \\
\hline Below $185 \%$ of poverty & 1300 & 34.8 & 600 & 52.1 \\
\hline Above $185 \%$ of poverty & 2450 & 65.2 & 550 & 47.9 \\
\hline \multicolumn{5}{|l|}{ Race } \\
\hline White, non Hispanic & 1700 & 44.9 & 450 & 40.4 \\
\hline Black & 550 & 15.2 & 200 & 20.2 \\
\hline Hispanic & 650 & 16.9 & 200 & 18.1 \\
\hline Asian, non Hispanic & 450 & 11.8 & 100 & 7.3 \\
\hline Pacific Islander & 50 & 0.5 & 0 & 0.5 \\
\hline American Indian, Alaskan Native & 100 & 2.8 & 50 & 3.5 \\
\hline More than one race & 300 & 7.7 & 100 & 10 \\
\hline \multicolumn{5}{|l|}{ Mother's Age } \\
\hline $19-24$ & 350 & 10 & 200 & 17.8 \\
\hline $25-30$ & 900 & 25 & 350 & 32.7 \\
\hline $31-36$ & 1250 & 34.5 & 300 & 26.3 \\
\hline $37-42$ & 850 & 23.4 & 200 & 17.7 \\
\hline $43+$ & 265 & 7.2 & 50 & 5.5 \\
\hline \multicolumn{5}{|l|}{ Mother's Education } \\
\hline Less than High School & 250 & 7.2 & 150 & 12.7 \\
\hline High School or Equivalent & 850 & 22.7 & 350 & 29.2 \\
\hline Some college or equivalent & 1200 & 32.2 & 400 & 37.1 \\
\hline BA degree or equivalent & 700 & 19.4 & 150 & 12.7 \\
\hline Beyond BA degree & 650 & 17.3 & 100 & 6.9 \\
\hline \multicolumn{5}{|l|}{ Marital Status } \\
\hline Married & 2500 & 67.2 & 650 & 57.9 \\
\hline Divorced & 250 & 7.2 & 100 & 6.8 \\
\hline Never Married & 650 & 17.5 & 300 & 27.3 \\
\hline \multicolumn{5}{|c|}{ Number of paid hours worked per week } \\
\hline & & $37.2(24.6)$ & & $32.8(23.2)$ \\
\hline \multicolumn{5}{|l|}{ Number of children in household } \\
\hline 1 & 800 & 21.5 & 200 & 19.6 \\
\hline 2 & 1650 & 44.8 & 450 & 38.9 \\
\hline 3 & 850 & 22.6 & 300 & 25.4 \\
\hline $4+$ & 150 & 3.4 & 50 & 5.1 \\
\hline
\end{tabular}

${ }^{1}$ Per U.S. Department of Education privacy rules, N's are rounded to the nearest 50. 
Mothers in this sample ranged in age from 19 to 69, with a mean age of 30.31 years ( $S D=5.57$ ). Approximately $44 \%$ of mothers indicated their child's race as non-Hispanic White, $16 \%$ as Black, $17 \%$ as Hispanic, $11 \%$ as Asian, $3 \%$ as American Indian, and $8 \%$ as multiracial. Sixty five percent $(n=3150)$ of mothers were married, while 30\% reported being separated, divorced or never married. Seventy seven percent $(n=3350)$ of mothers reported working daytime shifts, $10 \%$ reported working evening shifts $(n=450), 4.5 \%$ reported working night shifts $(n=220)$, and $8.5 \%$ reported working rotating shifts $(n=400)$. Approximately $39 \%$ of families are classified as low-income, which is defined as living below $185 \%$ of the poverty threshold. In an effort to yield nationally representative estimates, various sampling weights were included in the present study. Sampling weights help to "correct" for over- or under- representation in sample selection. These weights also account for nonresponse among sample participants and adjust for the fact that different groups of children and families had different likelihoods of being included in the study.

\section{Measures}

Descriptive statistics for sample measures are displayed in Table 2.

\section{Maternal nonstandard hours}

Questions about the timing of work were asked of mothers who reported being employed at Wave 3. Mothers were asked, "Which of the following best describes the hours you usually work at your main job?" Six mutually-exclusive choices were provided: daytime (6:00 a.m.-6:00 p.m.), evening (2:00 p.m.-12:00 a.m.), night (9:00 p.m.-8:00a.m.), rotating (one that changes periodically from days to evenings or nights), split (one consisting of two distinct periods each day), and other (mothers were prompted to specify). A maternal nonstandard work schedule variable was created to indicate whether or not mothers worked a nonstandard schedule (coded as 1) or a standard schedule (coded as 0). Mothers were coded as having a nonstandard work schedule if they worked evenings, nights, rotating shifts, or split shifts; and were coded as having a standard working schedule if they reported working primarily a daytime shift. Additionally, three dummy variables (coded as 0/1) were created to indicate specific types of maternal nonstandard work schedules (evening shifts, night shifts, and rotating/split shifts).

\section{Early care and education learning environments}

To capture the extent to which children attended an educationfocused early care setting, eight variables served as indicator variables to the latent construct, 'early care and education learning environments.' These variables (described in detail below) come from both the parent interview as well as the Wave 3 Early Care and Education Provider (ECEP) questionnaire, which was developed specifically for the ECLS-B to make informed comparisons across different child care settings. The ECEP was a computerassisted telephone interview (CATI) and was administered to the primary child care provider, as indicated by parents in the parent interview. ECEP interviews lasted 45 minutes for home-based and nonparental care providers, and 55 minutes for center-based care providers. The questionnaire captured information about the care setting, staff, and services offered (e.g. the quality of the learning environment including learning materials, curricula and activities, and information about the caregiver's training and experiences).

Table 2: Descriptive statistics for analysis variables.

\begin{tabular}{|c|c|c|}
\hline Variables & $\mathbf{N}^{1}$ & $\begin{array}{c}\text { Frequency (\%) or } \\
\text { M(SD) }\end{array}$ \\
\hline \multicolumn{3}{|l|}{ ECE Learning Environment } \\
\hline Literacy Mean & 3600 & $3.52(0.98)$ \\
\hline Math Mean & 3600 & $3.13(1.15)$ \\
\hline Specialized Degree & 2700 & $.53(.50)$ \\
\hline Caregiver Education & 3600 & $3.75(1.54)$ \\
\hline Number of Books & 3600 & $3.06(1.30)$ \\
\hline Computer Use & 3600 & $.61(.49)$ \\
\hline Hours in Center Care & 4850 & $19.50(16.89)$ \\
\hline Primary Care Arrangement & 4850 & $1.51(.66)$ \\
\hline \multicolumn{3}{|l|}{ Home Learning Environment } \\
\hline Minutes reading & 4750 & $2.15(1.02)$ \\
\hline Parent-child play & 4850 & $3.81(1.28)$ \\
\hline Number of books & 4850 & $2.92(1.28)$ \\
\hline Read books & 4850 & $3.07(.85)$ \\
\hline Tell stories & 4850 & $2.68(.91)$ \\
\hline Visit library & 4850 & $.40(.49)$ \\
\hline Computer use & 4850 & $.61(.49)$ \\
\hline \multicolumn{3}{|l|}{ Cognitive Development } \\
\hline Color Knowledge & 4850 & $8.4(2.50)$ \\
\hline Reading & 4850 & $23.9(9.31)$ \\
\hline Math & 4850 & $27.88(9.42)$ \\
\hline \multicolumn{3}{|l|}{ Maternal Work Schedule } \\
\hline Evening & 500 & 9.8 \\
\hline Night & 200 & 4.6 \\
\hline Rotating/Split & 400 & 8.8 \\
\hline Standard & 3700 & 76.8 \\
\hline
\end{tabular}

${ }^{1}$ Per U.S. Department of Education privacy rules, N's are rounded to the nearest 5 .

Center-based care as primary arrangement: As part of the Wave 3 interview, parents were asked if they currently had any regular early care and education arrangements for their child, and if so, what types of settings these were (e.g. Head Start, centerbased care, and home-based care with a nonrelatives, homebased care with a relative). If children spent time in multiple care 
arrangements, parents were asked to identify a primary care arrangement (i.e. the setting where the child spent the most time). The original variable was re-coded in the current study to capture whether children spent the most time in center-based care (coded as 1) or in home-based care, informal care, or no care (coded as 0 ).

Weekly hours in center-based care: Parents who indicated that their child attended some form of child care were then asked how many hours per week their child spent in their primary care setting. A continuous variable was created to reflect the amount of time children spent in center-based care (center-based care or Head Start). Children whose primary arrangement was homebased were assigned a " 0 " for this variable.

Frequency of literacy activities: Early care and education providers reported on the frequency of classroom literacy activities at Wave 3. Specifically, providers were asked, "How often do the children in your class/care do each of the following reading and language activities?" Response options consisted of Never (coded as 0), About once a month or less (coded as 1), Two or three times a month (coded as 2), Once or twice a week (coded as 3), Three or four times a week (coded as 4), and Everyday (5). A mean score was created based on 11 reading and language activities. $(\mathrm{M}=3.52, \mathrm{SD}=.98)$.

Frequency of math activities: Information about the frequency of classroom math activities was obtained from early care and education providers at Wave 3. Specifically, providers were asked, "How often do the children in your class/care do each of the following math activities?" Response options consisted of Never (coded as 0), About once a month or less (coded as 1), Two or three times a month (coded as 2), Once or twice a week (coded as 3), Three or four times a week (coded as 4), and Everyday (5). A mean score was created based on 10 math activities $(M=3.13, S D=1.2)$.

Caregiver education level: Early care and education providers were asked to indicate their level of education from among 22 categories. For the current analysis, some of the response options were collapsed in order to create a variable that encompasses six education levels: Less than high school (coded as 1), High school diploma or equivalent (coded as 2), Some college, but no degree (coded as 3), Associate's degree (coded as 4), Bachelor's degree (coded as 5), and Graduate or professional degree (coded as 6).

Specialized caregiver degree: Early care and education providers were asked to indicate whether or not they have a degree in early childhood education or a related field (other than a Child Development Association [CDA] credential). The analysis variable is coded such that 0 indicates no specialized degree and 1 indicates a specialized degree.

Number of books: Primary caregivers were asked to identify an approximate number of books available to children in the care setting. The original continuous variable (which ranged from 0 to $900)$ was re-coded into quintile ranks $(1=0-15,2=16-30,3=31$ $60,4=61-100,5=101$ or more books).

Computer availability: Early care and education providers were asked if a computer was available for use among children. The analysis variable is coded such that $0=$ no and $1=y e s$.

\section{Home learning Environment}

The home learning environment was assessed using a subset of the Home Observation for Measurement of the Environment (HOME) inventory. The HOME was designed to assess the safeness of the physical environment, the provision of learning opportunities and cognitive stimulation, the sensitivity and responsiveness of the mother, and disciplinary styles enforced by mothers (Bradley, 1985; Bradley et al., 1988). In the current study, a latent variable, home learning environment was constructed using seven indicators that broadly parallel those used to assess the early care and education learning environment.

Reading quantity: Parents were asked to indicate how many minutes per day the focal child was read to by an adult in the household. The original continuous variable was re-coded into quartile ranks $(1=0-15$ minutes, $2=16-25$ minutes, $3=26-40$ minutes, and $4=41$ minutes or more).

Parent-child play with manipulative: Mothers were asked to report how often they played together with the focal child using toys for building such as blocks, Lincoln logs, Tinkertoys, or Legos. The original variable was reverse coded so that higher values reflected higher incidences of playtime $0=$ not at all, $1=$ rarely, $2=\mathrm{a}$ few times a month, 3 = a few times a week, $4=$ about once $\mathrm{a}$ day, and $5=$ more than once a day).

Number of books: Mothers were asked to identify an approximate number of books available to children in the home. The original continuous variable (which ranged from 0 to 900) was re-coded into quintile ranks $(1=0-15,2=16-30,3=31-60,4=61-100,5$ $=101$ or more books). This re-coded variable is identical to the education-focused early care setting number of books variable.

Story time: Mothers were asked to report how often they engage in story telling with the focal child within the past week $(1=$ not at all, $2=$ once or twice, $3=$ three to six times, and $4=$ everyday).

Library visits: Mothers were asked to indicate whether or not the child had visited a public library within the past month. The original variable was re-coded so that $0=n o$ and $1=y e s$.

Computer use: Mothers were asked to indicate whether or not there was a computer in the home that the child uses. The original variable was reverse coded $(0=$ no; $1=$ yes $)$.

\section{Children's early academic skills}

A latent variable for children's early academic skills was constructed using three indicators: early reading ability, early math ability, and color knowledge. Together, these assessments provide a detailed portrait of academic skills early in the life course.

Early reading ability: During the Wave 3 home visit, preschoolaged children's early reading skills were directly measured and administered by trained project personnel using a test composed of 37 multiple choice items representing the following content areas: receptive letter recognition, expressive letter recognition, letter sounds, recognition of simple words, phonological awareness, knowledge of print conventions, and matching words. 
A three parameter (one parameter representing item difficulty, one parameter representing item sensitivity, and one parameter accounting for probability of choosing the correct choice by guessing) logistic item response theory (IRT) model was applied to all reading item responses from all children in the ECLS-B sample, and a composite reading score was then computed for each individual ( $\alpha=.84$ ) (for details see [33]).

Early math ability: The early math domains measured at Wave 3 are a subset of those measured in the kindergarten wave of the ECLS-B: number sense, geometry, counting, operations, and patterns. As with the reading ability measure, an IRT model was applied to all mathematic item responses from all children in the preschool wave. A composite math score was computed for each child $(\alpha=.89)$.

Color knowledge: To assess color knowledge at Wave 3, children were presented five bears and were asked to name the color of each (each correct answer receiving 2 points). If the child could not name the color of the bear during the initial attempt, the evaluator followed up with, "Can you find the [blue] bear?" (each correct answer receiving 1 point) ( $\alpha=.82)$.

Family income status: Total household income at Wave 3 was compared to U.S. Census poverty thresholds for 2005, which vary by household size. For example, a household of four with a household income of $\$ 36,946$ was considered to be below 185 percent of the poverty threshold. Poverty status was coded as 1 (below poverty) and 2 (above poverty).

\section{Covariates}

Evidence suggests that nonstandard schedule occupancy is linked to a number of socioeconomic variables such as having a low income, low education level, single-parenthood status, and being a minority. Therefore, a number of covariates were included in the current study to better isolate the main and indirect effects. Child gender was coded such that $0=$ female and $1=$ male. Six dummy variables (coded as $0 / 1$ ) were created to indicate race and ethnicity (White (non-Hispanic) (omitted), Black (non-Hispanic), Hispanic, Asian/Pacific Islander, American Indian/Alaskan Native, and Multiracial). Mother's age was coded such that $1=19$ $-24,2=25-30,3=31-36,4=37-42$, and $5=43$ or older. Mother's education was coded such that $1=$ Less than high school, $2=$ High school or equivalent, $3=$ Some college or equivalent, $4=B A$ or equivalent, and $5=$ Beyond BA degree. Mother's marital status was coded such that $1=$ Married and $0=$ Unmarried (omitted). Number of children was coded such that $1=1,2=2,3=3$, and $4=4$ children or more. Full-time status (coded as $0 / 1$ ) indicates the number of hours per week mothers reported working (i.e. part-time $=34$ hours or less per week and full-time $=$ more than 35 hours per week). Child gender and child race were assessed at baseline. All other covariates were captured at Wave 3.

\section{Plan of analysis}

Structural equation modeling (SEM) techniques were used to test the hypothesized associations between variables using LISREL 8.8 [34]. Structural equation modeling is appropriate for this study because it allows for modeling latent, or unobserved, variables and offers a number of benefits not available in OLS regression approaches. For example, parameter estimates based on latent factor scores are calculated with a consideration for measurement error associated with observed independent and dependent variables [35]. Model fit of the proposed structural equation models were evaluated by examining the chi-square statistic and three alternative fit indices. Several steps were utilized to test for mediation in the current study. Drawing from Baron and Kenny's [36] approach, to test a mediator the first regression must show that the independent variable affects the mediator, the second that the independent variable affects the dependent variable, and the third that the mediator affects the dependent variable. For full multiple mediation, the fourth regression must show that after controlling for the mediators (early care and education learning environments and home learning environment), the independent variable (maternal nonstandard work schedules) no longer significantly predicts the dependent variable (children's early academic skills). Partial mediation occurs if the effect of the predictor variable on the outcome variable is reduced, but still significant, when the mediators are controlled [36]. Mediation was also tested by using the Sobel [37] test to examine the decrease of the effect of the predictor variable on the outcome variable, after accounting for the mediating variables. The moderating effect of family income status was also tested in the current study. An interaction variable was created among maternal nonstandard work schedules and family income status. Moderation was tested by examining the overall fit of two models, one where the interaction variable was included in the main structural model, and one where the interaction variable was not included in the main structural model. A significant change in chi-square between the two models indicates that the associations between maternal nonstandard schedules, early care and education learning environments, home learning environment, and children's early academic skills vary as a function of the moderator

\section{Results and Discussion}

This section presents results from structural equation analyses that tested hypotheses related to

1. The direct effects of maternal nonstandard work schedules on children's early academic skills,

2. The role of early care and education learning environments as a mediator of the link between maternal nonstandard work schedules and children's cognitive development,

3. The role of home learning environment as a mediator of the link between maternal nonstandard work schedules and children's cognitive development, and

4. The role of poverty status as a moderator.

\section{Direct effects of maternal nonstandard work schedules on children's early academic skills}

According to the family stress model, the stress associated with working nonstandard schedules can compromise not only personal well-being, but the well-being of children. It was 
hypothesized that maternal nonstandard work schedules would be associated with lower levels of children's early academic skills, as indicated by lower color knowledge, reading, and math scores. To test this hypothesis, direct associations between maternal nonstandard work schedules (modeled as a manifest variable) and children's early academic skills were examined. This model provided moderate fit to the data $(\chi 2(11)=621.09, p=.00$; $\mathrm{CFI}=.92 ; \mathrm{RMSEA}=.14 ; \mathrm{SRMR}=.08)$. As expected, maternal nonstandard work schedules were negatively associated with children's early academic skills $(\beta=-0.05, S E=.06, p<.001)$. Standardized regression coefficients for the direct association between maternal nonstandard work schedules, children's early academic skills, and covariates are presented in Figure 2. Thus, the hypothesized negative association between maternal nonstandard work schedules and children's early academic skills was supported.

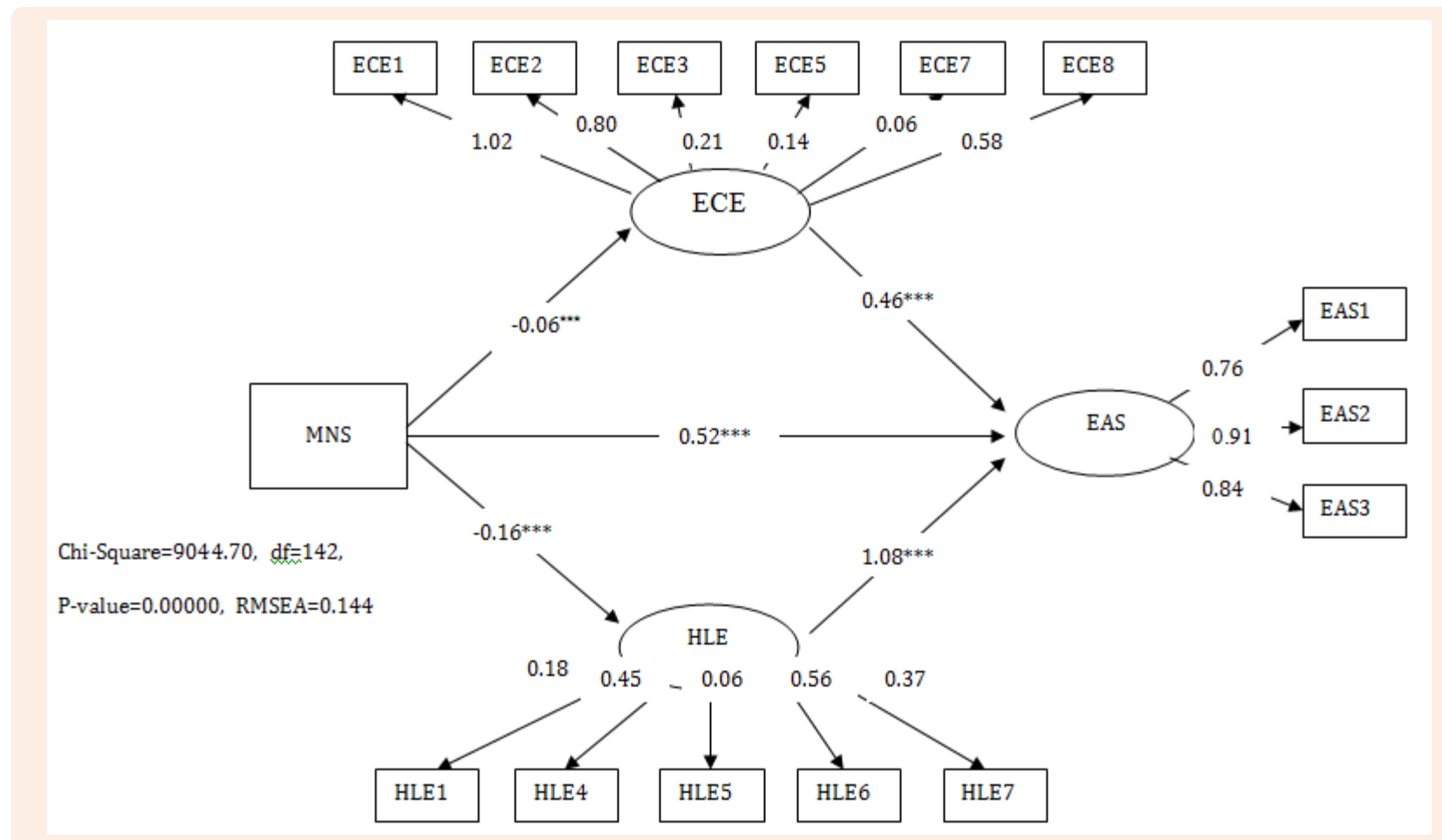

Figure 2: Standardized path coefficients for the associations among maternal nonstandard work schedules, early care and education learning environments, home learning environments, and children's early academic skills ( $\mathrm{N}=3050)$.

Note: Covariates not included in this figure

${ }^{*} \mathrm{p}<.05^{* *} \mathrm{p}<.01 * * * \mathrm{p}<.001$

\section{The mediating effects of early care and education learning environments and home learning environments}

It was hypothesized that any observed direct associations between maternal nonstandard work schedules and children's early academic skills would be explained in part by the learning environments that children experience in early care and education settings and at home. Specifically, it was hypothesized that early care and education and home learning environments would partially mediate the direct association between maternal nonstandard work schedules and children's early academic skills. There was empirical support for the hypothesis that the effect of maternal nonstandard work schedules on children's early academic skills was mediated by early care and education learning environments $(z=-3.23, p<.001)$. Maternal nonstandard work schedules were negatively associated with early care and education learning environments $(\beta=-.06, S E=.04, p<.05)$. Early care and education learning environments were positively associated with preschool-aged children's cognitive development ( $\beta=.46, \mathrm{SE}=.16, p<.05)$. There was also empirical support for the hypothesis that the effect of nonstandard maternal work schedules on children's early academic skills would be mediated by home learning environment $(z=-3.97, p<.001)$. Maternal work schedules were negatively associated with the home learning environment $(\beta=-.16, \mathrm{SE}=.01 p<.05)$. Home learning environment was positively associated with children's early academic skills $(\beta=1.08, \mathrm{SE}=11.64, p<05)$. The direct effect of maternal nonstandard work schedules on children's early academic skills remained significant once the mediators were included into the structural model and also changed in strength from negative to positive. Therefore, the hypothesis that early care and education learning environments and home learning 
environment would partially (rather than fully) mediate the relationship between maternal nonstandard work schedules and children's early academic skills was supported. Standardized regression coefficients are presented in Figure 3.

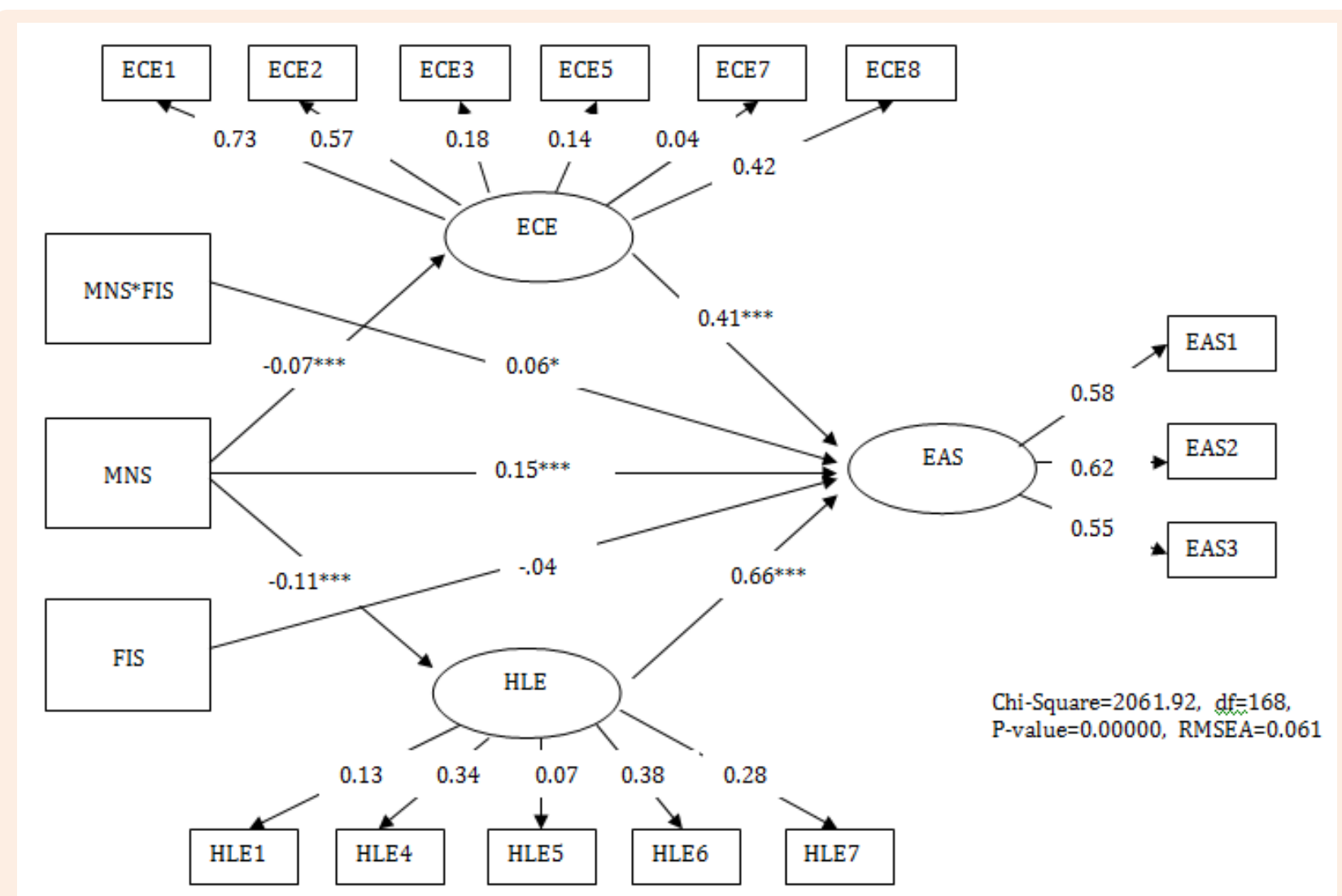

Figure 3: Standardized path coefficients for the associations among maternal nonstandard work schedules, early care and education learning environments, home learning environments, and children's early academic skills: Family income status as a moderator $(\mathrm{N}=3050)$. Note: Covariates not included in this figure.

${ }^{*} \mathrm{p}<.05^{* *} \mathrm{p}<.01{ }^{* * *} \mathrm{p}<.001$

\section{The moderating effects of family income status}

Drawing from recent extensions of family stress theory, it was hypothesized that family income status would influence the relationship among maternal nonstandard work schedules, learning environments, and children's early academic skills such that children of mothers working nonstandard schedules in the context of low family income would exhibit lower academic skill scores than children of mothers working nonstandard schedules in more advantaged circumstances. To test this hypothesis, an interaction variable among maternal work schedule and family income status was included in the second structural model. Specifically, children's early academic skills was regressed onto three manifest variables - maternal nonstandard work schedules, family income status, and maternal nonstandard work schedules *family income status. This model provided a moderately reasonable fit to the data $(\chi 2(168)=2061.92, p=$ .00 ; $\mathrm{CFI}=.78$; RMSEA $=.06$; SRMR $=.06$ ). The standardized path coefficients were slightly lower than those in the previous model and exhibited associations in the same direction as the previous model. The interaction variable (i.e. maternal nonstandard schedules *family income status) was positively associated with children's early academic skills $(\beta=.06, S E=.20, p<.05)$. The path from family income status to children's early academic skills was not significant $(\beta=-0.04, S E=.32, \mathrm{p}=\mathrm{ns})$. A chi-square difference test of this model compared to one without family income status and the interaction term was conducted to determine whether or not family income status served as a moderator. The change in chisquare statistic was not significant $(\Delta \chi 2=-6982.78, \Delta \mathrm{df}=26, p=$ ns). Although the chi-square difference test was not significant, results provide some indication of moderation by family income status. Standardized regression coefficients are presented in Figure 3.

\section{Type of nonstandard work schedule}

The next structural model tested the extent to which the type of maternal nonstandard work schedule influences early care and education learning environments, home learning environments, and children's early academic skills. Specifically, evening, night, and rotating/split shifts were each treated as independent manifest variables with standard schedules as the omitted group. 
This model fit the data reasonably well $(\chi 2(178)=2119.33, p$ $=.00$; CFI $=.78$; RMSEA $=.06$; SRMR $=.05$ ). The results of this model provide evidence for the hypothesis that some types of nonstandard schedules are negatively associated with children's cognitive outcomes because they reduce children's access to educationally-focused learning environments in care settings and at home. Evening, night, and rotating/split shifts were negatively associated with early care and education learning environments $(\beta=-.03, \mathrm{SE}=.06, p<.05 ; \beta=-.11, \mathrm{SE}=.09 p<.05$; and $\beta=-.08$, $\mathrm{SE}=.05, p<.05$, respectively). Evening shifts and night shifts were negatively associated with home learning environments $(\beta=-.21$, $\mathrm{SE}=.01, \mathrm{p}<.05$, and $\beta=-.16, \mathrm{SE}=.02, p<.05$, respectively). Yet, rotating/split shifts were positively associated with home learning environments $(\beta=.11, \mathrm{SE}=.01, p<.05)$. Early care and education learning environments and home learning environment were both positively associated with children's early academic skills ( $\beta$ $=.42$, SE $=.29 p<.05$; and $\beta=.67, S E=7.89, p<.05$, respectively). Evening shifts were positively associated with children's early academic skills ( $\beta=.11$, SE $=.02, p<.05$ ). Surprisingly, rotating/ split shifts and night shifts, were also positively associated with children's early academic skills $(\beta=.13, S E=.02, p<.05$; and $\beta=$ $.08, S E=.02, p<.05$ ). Overall, there was empirical support for the hypothesis that night and rotating/split shifts would be negatively associated with children's early academic skills. Standardized regression coefficients for all paths are presented in Figure 4.

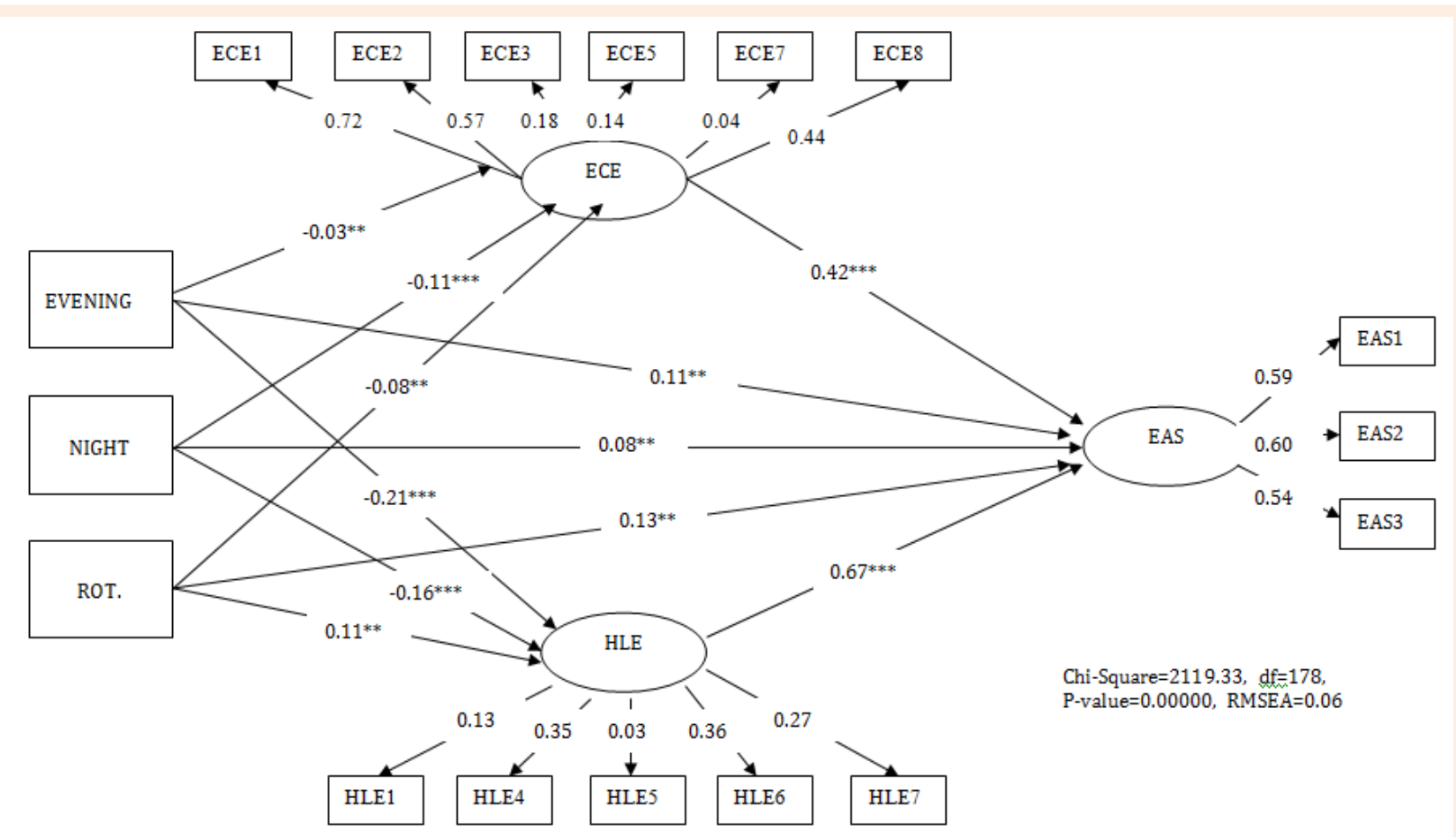

Figure 4: Standardized path coefficients for the associations among maternal nonstandard work schedule types, early care and education learning environments, home learning environments, and children's early academic skills ( $N=3050)$.

Note: Covariates not included in this figure.

${ }^{*} \mathrm{p}<.05^{* *} \mathrm{p}<.01 * * * \mathrm{p}<.001$

\section{Discussion}

\section{The direct association between maternal nonstandard work schedules and children's early academic skills}

The influx of mothers with young children occupying evening, night, or rotating work shifts has sparked a great deal of interest among researchers interested in issues related to the impact of this social trend. A prominent question centers on how maternal nonstandard work schedules influence young children's wellbeing. Therefore, the first goal of the study was to test the direct association between maternal nonstandard work schedules and children's early academic skills. A negative association was hypothesized, such that maternal nonstandard work schedules would be associated with lower levels of children's early academic skills. As expected, there was a significant negative association between maternal nonstandard work-schedules and children's early academic skills. That is, children whose mothers work nonstandard schedules scored lower on standardized measures of early academic skills than those whose mothers worked primarily standard weekday hours. Although the strength of the association was relatively weak, these results suggest that maternal nonstandard work schedules may be harmful for young children's development. While other researchers have examined the link between maternal nonstandard work schedules and child well-being, the period of development examined is usually middle childhood or adolescence, and the outcome of interest has often been behavioral or socioemotional [6-40]. The results 
of the current study are consistent with the few studies that have explored how maternal nonstandard work schedules are related to children's early academic skills [6]. These findings are particularly important, as early childhood is a vital period of development that sets the stage for children's future trajectories. Additionally, the outcome of focus in the current study (i.e. cognition) has been identified as one of the more important predictors of children's school readiness and later school success. These results build on earlier arguments that maternal employment may be detrimental for children's well-being and underscore the need to further explore the type of work shift employed, and the interconnections between work and family.

\section{The mediating roles of early care and education learning environments and home learning environments}

Extensions of the family stress theory have been used as a framework for understanding how maternal nonstandard work schedules influence family functioning. The theory posits that adaptive resources aid in buffering the effects of pile-up experienced by a family and can ultimately aid in preventing maladaptation. Early learning environments may serve as adaptive resources for young children whose mothers work nonstandard schedules. Children exposed to favorable early learning environments, despite the presence of maternal nonstandard schedules, are more likely to achieve bonadaptation (i.e. higher levels of early academic skills). On the other hand, in general, nonstandard schedules may make it less likely that young children experience educationally-focused early learning environments. This is primarily due to the limited amount of formal care, which is linked to favorable academic outcomes, available during nonstandard hours. This perspective informed the expectation of the current study that early care and education learning environments and home learning environments would partially mediate the relationship between maternal nonstandard work schedules and children's early academic skills, suggesting that early learning environments are potential adaptive resources for mothers experiencing pile-up and stress associated with working nonstandard schedules. In general, the study hypotheses were supported, suggesting that early care and education learning environments and home learning environments partially mediated the relationship between maternal nonstandard work schedules and children's early academic skills in this nationally representative sample of young American children. Maternal nonstandard work schedules were negatively associated with early care and education and home learning environments. That is, mothers who work nonstandard schedules used early care and education settings that provided fewer learning experiences than mothers working primarily standard schedules. This finding offers evidence that mothers who work nonstandard schedules may be lacking the adaptive resources needed to provide children with learning opportunities that promote cognitive development. This finding is especially imperative in light of findings from Han [29], which revealed that, although maternal standard work schedules were linked to higher incidences of children enrolled in day care centers by age three, children whose mothers worked nonstandard hours had higher occurrences of father-care or care arrangements other than center-based care. Han's sample was more advantaged in terms of income and included a large number of dual-earner families. Thus, one advantage of the current study is the ability to examine these linkages for a broader sample and ask whether associations between work schedules and child academic skills vary by family income status. Additionally, the current study looked beyond the type of care and included important features of early learning environments that promote optimal learning experiences for young children. Consistent with prior research, maternal nonstandard work schedules were negatively associated with home learning environments [41]. It appears as if the parenting-related costs of nonstandard work schedules are largely direct. Previous work assessing the direct effects of maternal nonstandard work schedules and the overall home environment has taken conditions of work into account. Nonstandard work schedules are often characterized by conditions that are more common in less well-paid jobs. These jobs are low in complexity and are characterized by routinization, low autonomy, and heavy supervision. Theorists and researchers contend that these working conditions erode intellectual flexibility and exacerbate psychological distress among mothers. Consequently, the distress created by low occupational standing has obvious intergenerational consequences such that parents with higher levels of distress display less attentive, responsive, and stimulating parental behavior and provide less optimal child-rearing environments compared to mothers with higher paying jobs in occupations characterized by more complexity [20]. Adverse socioeconomic conditions may also produce psychological stress that influences parent-child interactions [42]. Following these arguments, the pile-up associated with working a nonstandard job may constrain a mother's ability to provide an adequate home learning environment. The finding that early care and education learning environments and the home learning environment were positively associated with children's early academic skills speaks to the potential compensatory effect of multiple learning environments highlighted by Watamura [43] and others in recent years. Essentially, early care and education and home learning environments are important contributors to children's development. Several empirical studies have illustrated the importance of child care and home environments for many aspects of children's well-being (e.g., [19-47]). It is well established that child care and home environments lacking in resources can have independent negative effects on child development, with particularly strong effects for home characteristics [24]. Fewer studies have revealed significant combined effects of home and child care factors, and several have focused only on low-income populations [48]. In recent years, these research efforts have merged in an effort to examine the combined contextual influences of child care and home experiences [43]. Consistent with recent investigations, the current study supports hypotheses that suggest a compensatory environmental effect for children's development. Although maternal nonstandard work schedules were negatively linked to both learning environments, each setting was positively associated with children's early academic skills. Taken together, this pattern of findings suggests that early care and education learning environments, as captured by characteristics that promote favorable academic learning experiences, are worth considering in understanding the development of children whose 
mothers work nonstandard schedules. Children growing up in homes that lack learning materials and resources, although vulnerable to the negative effects of maternal nonstandard work schedules, may be buffered by exposure to early care and education learning environments.

\section{The influence of the type of maternal nonstandard schedule}

The literature on nonstandard work has only recently begun to tease apart the effects of the type of nonstandard shift employed. Empirical evidence suggests that night and rotating shifts are particularly harmful to family functioning. Specifically, the irregular sleep patterns, stress, depression, and disrupted family routines associated with these schedules may reduce the likelihood of consistent opportunities to nurture children's learning experiences at home [17-41]. The type of nonstandard shift also matters for children's early care and education experiences. The availability of center-based care is extremely limited during a night shift, whereas children may have opportunities to experience center-based care during evening or rotating shifts. To build on this literature, it was hypothesized that the type of nonstandard shift would matter, such that night and rotating/split shifts would be negatively associated with children's early academic skills. Because center-based care is harder to secure during night hours and because research suggests that less formal arrangements provide less cognitively stimulating environments, a negative association between early education and care learning environments was hypothesized. Further, mothers who work night schedules are more likely to sleep during the day - limiting opportunities to provide a cognitively stimulating home environment. Therefore, a negative association between night shifts and home learning environments was also expected. Similarly, the irregularity associated with working rotating shifts may hinder a mother's ability to secure center-based care that is consistent and to provide regular home learning opportunities. In general, results supported this hypothesis. As expected, night and rotating shifts were negatively associated with children's early care and education learning environments. Evening shifts were also negatively associated with children's early care and education learning environments. These shifts may pose different barriers to securing favorable child care, compared to standard shifts. In fact, evidence from a qualitative study revealed that mothers often encountered greater difficulties in arranging child care and experienced unwanted income instability when their work schedules varied unexpectedly [49]. Thus, the unpredictability associated with rotating shifts may lead to inconsistent care, or lower incidences of center-base care usage. Although all three shifts were negatively related to early care and education learning environments, this setting may still serve as an adaptive resource to mothers. For example, night shifts had the strongest association with early care and education learning environments, whereas evening shifts had the weakest association. It could be that children whose mothers work evening shifts are more exposed to favorable early care and education learning environments, compared to children whose mothers work night and rotating/ split shifts. Another plausible explanation for the stronger night shift effect is the inability to afford care during daytime hours. Care arrangements must be secured during the night shift hours (particularly in the case of single mothers and mothers with fewer resources) and if all resources are funneled into overnight care then other forms of care may not be a viable option.

To the extent that evening, night, and rotating/split shifts prevent experiences in early care and education learning environments among preschool-aged children, the home learning environment is a setting that may buffer those effects [43-50]. Results of the current study indicated that evening and night shifts were negatively associated with the home learning environment. Mothers who work evening shifts are usually not home for dinner or other evening activities. Therefore, opportunities to facilitate children's learning are missed, especially if children are in some form of nonparental care during the day. The finding that night shifts were negatively associated with home learning environments was not surprising. A substantial body of literature suggests that working the night shift takes a mental toll on employees [51]. Specifically, higher levels of fatigue, job-related stress, and perceived work-family are associated with night shift work. Therefore, the fatigue and parental stress associated with working the night shift may prevent mothers from engaging in meaningful parent-child interactions, resulting in less favorable home learning environments. Consistent with prior research, rotating shifts were positively associated with home learning environments. Recent work by Lleras [52] revealed a positive association between rotating shift occupancy and home learning environments of single mothers with preschool-aged children. Similarly, Han and Fox (2011) found that children whose mothers worked rotating shifts had significantly higher reading and math scores. Moreover, mothers who employed rotating shifts tended to be more socioeconomically advantaged compared to mothers who had ever worked either evening or night shifts. Thus, although rotating shifts can be stressful in the sense that mothers may not be able to plan being at home when they want or need to be [11], there may be beneficial consequences for children. Perhaps mothers take advantage of opportunities to engage in activities that promote learning when rotating shifts do permit time with children.

\section{Conclusion}

The results from the current study make an important contribution to the literature by focusing on the effects of maternal nonstandard work schedules for children's early academic skills. These findings augment the small amount of existing research on maternal nonstandard work schedules and child well-being. The results raise concerns about the effects of maternal nonstandard work and are consistent with a body of literature that points to beneficial effects of children's exposure to early learning environments. If the negative relationship between maternal nonstandard work schedules (i.e. night and rotating/ split shifts) and early care and education learning environments is due to the limited options of center-based child care at these nonstandard times, then providing a greater availability of formal care arrangements for children whose mothers work nonstandard 
hours is imperative. In recent years, many corporations have implemented on-site child care during nonstandard hours for their employees. This is an initiative that should become more prevalent. From a policy perspective, it is critical to further explore how different early care and education settings may serve to protect children from low levels of stimulation at home. Caregivers and practitioners should be supportive and sensitive to the larger social and demographic influences of children's home learning environments. A policy initiative targeting the direct support of parents in their literacy- and math-promoting behaviors is a start Future research in this area would also benefit from studies that address why mothers employ nonstandard schedules and how decisions about child care are made. These studies may serve to parse out the differential effects among nonstandard schedule types (i.e. evening, night, and rotating). Also, the effects of a mother's work schedule is contingent upon whether a spouse or caregiver is home, awake, and energized enough to take care of the child (for families with more than one adult in the household). That is, the effects of maternal nonstandard work schedules are likely to vary by both the type of shift and the patterns of both parents' work schedules. Therefore, work schedules of other adults in the household should be taken into account in future investigations [29]. To address the limitation of the way that nonstandard work is measured, future research should consider the extent to which nonstandard work is voluntary. Factors such as spousal unemployment and job complexity might drive mothers to work nonstandard schedules that they may not have otherwise preferred. Qualitative studies have the potential to address this issue, as they may capture more thorough information about selection into nonstandard schedules not captured in quantitative surveys. Consistent with previous work, the current study revealed that certain types of work schedules pose greater conflicts for families than others. When it comes to nonstandard work, maternal night schedules appear to be problematic, particularly when it comes to the likelihood of a favorable early care and education learning environment. Given that increases in maternal nonstandard schedule occupancy will warrant more overnight child care availability, measures of child care quality should become more sensitive to what night care entails. For example, children will likely be put to bed and then monitored as they sleep through the night. As a result, measures of quality in such settings would be different from conventional measures of quality and will capture aspects of quality such as safety and adequate sleep arrangements. Therefore, policy initiatives that address new measures of quality are needed to account for the growing number of children and families affected by maternal nonstandard schedules. Results from the present study suggest that the intersection of maternal nonstandard work schedules with learning environments (an association that has been largely ignored in empirical literature) is linked to at least one aspect of school readiness, namely cognitive well-being. This study opens the door to a host of empirical questions to be examined in future research related to the links between maternal nonstandard work schedules and young children's development, and provides some direction for the selection of relevant demographic, dependent, and moderating variables. Further research is needed to replicate findings from this study, as well as explore additional schoolreadiness outcomes.

\section{Acknowledgement}

This manuscript is in loving memory of Dr. Deborah J. Cassidy, who contributed to its contents.

\section{Conflict of Interest}

None.

\section{References}

1. Rigby E, Ryan RM, Brooks-Gunn J (2007) Child care quality in different state policy contexts, Journal of Policy Analysis and Management 26(4): 887-907.

2. Center for Economic and Policy Research (2004) Working Moms and Child Care.

3. U.S. Department of Health and Human Services (2011) Health Resources and Services Administration, Maternal and Child Health Bureau. Child Health, Maryland.

4. (2008) Primary child care arrangements of preschoolers with employed mothers: Selected years, 1985 to 2005. US Census Bureau, USA.

5. Presser HB, Cox AG (1997) The work schedules of low-educated American women and welfare reform. Monthly Labor Review 120(4): 25-34.

6. Han WJ (2005) Maternal nonstandard work schedules and child cognitive outcomes. Child Development 76(1): 137-154

7. McCubbin HI, Patterson JM (1983) Family transitions: Adaptation to stress. In McCubbin HI, et al. (Eds.), Stress and the family: Coping with normative transitions. Brunner/Mazel, USA, p. 5-25.

8. Hill R (1949) Families under stress. Harper and Row, USA.

9. Riley LA, Glass J (2002) You can't always get what you want: Infant care preference and use among employed mothers. Journal of Marriage and Family 64(1): 2-15.

10. Joshi P, Bogen K (2007) Nonstandard schedules and young children's behavioral outcomes among working low-income families. Journal of Marriage and Family 69(1): 139-156.

11. Henly JR, Lambert S (2005) Nonstandard work and child care needs of low-income parents. In Bianchi S, et al. (Eds.), Work, family, health, \& well-being. Lawrence Erlbaum Associates, USA, pp. 473492.

12. Presser HB (1988) Shift work and child care among dual-earner American parents. Journal of Marriage and the Family 50Z(1): 133148.

13. Baydar N, Brooks-Gunn J (1991) Effects of maternal employment and child-care arrangements on preschoolers' cognitive and behavioral outcomes: Evidence from the children of the National Longitudinal Survey of Youth. Developmental Psychology 27(6): 932-945.

14. Han W, Waldfogel J, Brooks-Gunn J (2001) The effects of early maternal employment on later cognitive and behavioral outcomes. Journal of Marriage and Family 63(2): 336-354.

15. McMenamin TM (2007) A time to work: recent trends in shift work and flexible schedules. Monthly Labor Review 130: 3-15.

16. Hill EJ, Martinson V, Ferris M (2004) New concept part-time employment as a work-family adaptive strategy for women professional with small children. National council on Family Relations 53(3): 282-292. 
17. Presser HB (2003) Working in a 24/7 economy: Challenges for American families. Russell Sage Foundation, USA.

18. Capizzano J, Adams G (2000) The number of child care arrangements used by children under five: Variation across states. (New Federalism: National Survey of America's Families Series, No. B-12.) Washington, The Urban Institute, USA, p. 1-9.

19. Bronfenbrenner U, Morris PA (1998) The ecology of developmental processes. In Lerner RM (Ed.), Handbook of child psychology ( $5^{\text {th }}$ edn), Wiley, USA, pp. 993-1028.

20. Belsky J (1986) Infant day care: A cause for concern? Zero to Three $7(1): 1-7$.

21. Vandell D, Corasaniti M (1990) Variations in early child care: Do they predict subsequent social, emotional, and cognitive differences? Early Childhood Research Quarterly 5(4): 555-572.

22. Thornburg K, Pearl P, Crompton D, Ispa J (1990) Development of kindergarten children based on child care arrangements. Early Childhood Research Quarterly 5(1): 27-42.

23. Burchinal MR (1999) Child care experiences and developmental outcomes. Annals of Political and Social Science 563(1): 73-97.

24. NICHD Early Child Care Research Network (2002) Early child care and children's development prior to school entry: Results from the NICHD study of early child care. American Educational Research Journal 39(1): 133-164.

25. Duncan GJ, Ludwig J, Magnuson KA (2007) Reducing poverty through preschool interventions. Future Child 17(2): 143-160.

26. Chaudry A (2004) Putting children first: How low wage working mothers manage child care. Russell Sage Foundation, USA, pp. 1-368.

27. Bureau of Labor Statistics (2009) Labor force participation of mothers and fathers. U.S. Department of Labor, USA.

28. Folk KF, Yi Y (1994) Piecing together child care with multiple arrangements: Crazy quilt or preferred pattern for employed parents of preschool children? Journal of Marriage and the Family 56: 669-680.

29. Han, Wen-Jui (2004) Nonstandard work schedules and child care decisions: Evidence from the NICHD study of early child care. Early Childhood Research Quarterly 19(2): 231-256.

30. Henly JR, Lyons S (2000) The negotiation of child care and employment demands among low-income parents. Journal of Social Issues 56(4): 683-706.

31. Scott E, London A, Hurst A (2005) Instability in patchworks of child care when moving from welfare to work. Journal of Marriage and Family 67(2): 370-386.

32. Morrissey T (2008) Familial factors associated with the use of multiple child-care arrangements. Journal of Marriage and Family 70(2): 549-563.

33. Najarian M, Snow K, Lennon J, Kinsey S, Mulligan G (2010) Early childhood longitudinal study, birth cohort (ECLS-B): Preschoolkindergarten psychometric report. National Center for Education Statistics, USA, pp. 1-34

34. Joreskog KG, Sörbom D (1985) LISREL VI: Analysis of linear structural relationships by the method of maximum likelihood, instrumental variables, and least squares methods. ( $3^{\text {rd }}$ edn), Scientific software inc, USA.

35. Raykov T, Marcoulides GA (2006) A first course in structural equation modeling. ( $2^{\text {nd }}$ edn), Lawrence Erlbaum Associates, USA.
36. Baron RM, Kenny DA (1986) The moderator-mediator variable distinction in social psychological research: Conceptual, strategic, and statistical considerations. J Pers Soc Psychol 51(6): 1173-1182.

37. Sobel ME (1982) Asymptotic confidence intervals for indirect effects in structural equation models. Sociological Methodology 13: 290-312.

38. Barnett RC, Gareis KC (2007) Shift work, parenting behaviors, and children's socioemotional well-Being: A Within-family study. Journal of Family Issues 28(6): 727-748.

39. Davis KD, Crouter AC, McHale SM (2006) Implications of shift work for parent-adolescent relationships in dual-earner families. Family Relations 55(4): 450-460.

40. Strazdins L, Clements MS, Korda RJ, Broom DH, D'Souza RM (2006) Unsociable work? Nonstandard work schedules, family relationships, and children's well-being. Journal of Marriage and Family 68(2): 394-410.

41. Heymann SJ, Earle A (2001) The impact of parental working conditions on school-age children: The case of evening work. Community, Work \& Family 4(3): 305-325.

42. Conger RD, Wallace LE, Sun Y, Simons RL, McLoyd VC, et al. (2002) Economic pressure in African American families: A replication and extension of the family stress model. Dev Psychology 38(2): 179193.

43. Watamara SE, Phillips DA, Morrissey TW, McCartney K, Bub K (2011) Double jeopardy: Poorer social-emotional outcomes for children in the NICHD SECCYD experiencing home and child-care environments that confer risk. Child Develop 82(1): 48-65.

44. Moorehouse MJ (1991) Linking maternal employment patterns to mother-child activities and children's school competence. Developmental Psychology 27: 295-303.

45. NICHD Early Child Care Research Network (1997) Familial factors associated with the characteristics of non-maternal care for infants. Journal of Marriage and the Family 59(2): 389-408.

46. NICHD Early Child Care Research Network (2004) Type of child care and children's development at 54 months. Early Childhood Research Quarterly 19(2): 203-230.

47. NICHD Early Child Care Research Network (2005) Predicting individual differences in attention, memory, and planning in first graders from experiences at home, child care, and school. Dev Psychol 41(1): 99-114.

48. Votruba-Drzal E, Coley RL, Chase-Landsdale L (2004) Child care and low-income children's development: Direct and moderated effects. Child Dev 75(1): 296-312.

49. Lowe T, Weisner TS (2004) You have to push it-who's gonna raise your kids?: Situating child care in the daily routines of lowincome families. Children and Youth Services Review 26: 143-171.

50. Rodriguez ET, Tamis-LeMonda CS (2011) Trajectories of the home learning environment across the first 5 years: Associations with children's vocabulary and literacy skills at prekindergarten. Child Dev 82(4): 1058-1075.

51. Goodman WB, Crouter AC, The Family Life Project Key Investigators (2009) Longitudinal associations between maternal work stress, negative work-family spillover, and depressive symptoms. Family Relations 58(3): 245-258.

52. Lleras C (2008) Employment, work conditions, and the home environment in single-mother families. Journal of Family Issues 29(10): 1268-1297. 